\title{
ANTIBACTERIAL EFFICACY OF A MOUTHWASH CONTAINING HYDROXYAPATITE NANOPARTICLES ALONE OR IN COMBINATION WITH CHLORHEXIDINE/FLUORIDE
}

\author{
Omnia Magdy Mostafa *, Enas Hussein Mobarak **, \\ Mohamed Riad Farid** and Heba Ahmed El-Deeb***
}

\begin{abstract}
Aim: This study was carried out to evaluate the antibacterial activity of a mouthwash containing clusters of zinc-carbonate hydroxyapatite nanoparticles in combination with chlohexidine or fluoride.

Materials and methods: Antimicrobial agents used in this study were Chlorhexidine diacetate, Sodium fluoride powder and Dr.Wolff's Biorepair against Streptococcus mutans (MS). In this study, the relative antimicrobial efficacy of newly introduced zinc-carbonate hydroxyapatite nanoparticels containing mouthwash, chlorhexidine, sodium fluoride and their combination against MS was tested. The MS was inoculated onto its specified culturel media. Agar diffusion test is done. The inhibition zone diameters were measured. Mean inhibition zone diameters were recorded and statistically analyzed
\end{abstract}

Result: For the effect of the tested antibacterial on the Streptococcus mutans, results showed that the mean diameter and standard deviation of inhibition zone $(\mathrm{mm})$ for chlorhexidine $(\mathrm{CHX})$ was 23.9 (2.04) mm, sodium fluoride $(\mathrm{NaF})$ was $12.2(0.75) \mathrm{mm}$, hydroxyapatite microclusters containing mouthwash (HAPMC) was 18.2 (1.3) mm, HAPMC+CHX was 22.5 (2.6) $\mathrm{mm}$ and $\mathrm{HAPMC}+\mathrm{NaF}$ was $18.7(1.8) \mathrm{mm}$.

Conclusion: Hydroxyapatite microclusters containing mouthwash had a potential antimicrobial activity against MS alone or in combination with other antimicrobials.

\section{INTRODUCTION}

Clinical decision-making and the balance between preventive and surgical intervention have become an important part of daily dental practice ${ }^{(1)}$. In the era of these medical models of caries treatment renewed interest in developing an antimicrobial approach for the management of dental caries. In conjunction with this concept, control and prevention of caries has been sought by reducing the number of colonizing bacteria. Reducing their

* B. D. Sc. (Cairo University, 2008)

** Professor, Operative Dentistry Department , Faculty of Oral and Dental Medicine, Cairo University

*** Associate Professor, Operative Dentistry Department, Faculty of Oral and Dental Medicine, Cairo University 
level in the oral cavity will provide an additional rationale for the prevention of dental caries ${ }^{(2)}$

Chlorhexidine (CHX) has been known as an excellent broad spectrum antibacterial compound ${ }^{(3)}$. Nevertheless, the reported frequent side effects including taste perception alteration and an increase in tooth discoloration ${ }^{(4,5)}$ makes the use of $\mathrm{CHX}$ in dental practice questionable.

Also, fluoride is one of the most important and effective component in dental caries prevention programs ${ }^{(6)}$.The mechanisms by which fluoride prevents dental caries may involve at least two major routes ${ }^{(7)}$; inhibition of tooth mineral dissolution by acid, and enhancement of remineralization in carious lesions. In addition, many studies have also shown that fluoride can affect the biological ability of Streptococcus mutans which is the one of the causative factor of dental caries ${ }^{(8,9)}$.

Recently, hydroxyapatite microclusters containing mouthwash is proved as remeneralizing and desensitizing agents by many studies ${ }^{(10)}$. It was reported that it contains some components which might have antibacterial effect ${ }^{(11)}$. These newly biological and biomimetic approaches are required to optimize the prevention of caries ${ }^{(12,13)}$.

The combination between the antibacterial agents and hydroxyapatite nanoparticles in one mouthwash appearing attractive solution. Therefore, a study focusing on the potential antibacterial activity of an accredited mouthwash containing clusters of zinc-carbonate hydroxyapatite nanoparticles in combination with chlorhexidine or fluoride might be of benefit.

\section{MATERIALS}

Streptococcus mutans (MS) (ATCC 25175) Strain was obtained from microbiological resources center (Cairo MERCIN, Faculty of Agriculture, Ain Shams University, Cairo, Egypt).Antimicrobial agents used in this study were Chlorhexidine diacetate (Serva Electrophoresis, GmbH-69115
Heidelberg, Germany), Sodium fluoride powder (Sigma-Aldrich chemistry, St. Louis, Missouri, USA) and Dr.Wolff's Biorepair (Clusters of zinccarbonate hydroxyapatite nanoparticles) (Dr. Kuret Wolff, Bielefeld, Bologna-Italia)

\section{METHODS}

\section{Determenation of bacterial concentration}

Serial dilutions of each bacterial strain were done. Swab of the cultivated bacteria was mixed in $100 \mathrm{ml}$ of broth of the specific selective media then the suspension was placed in a shaker for three hours.The optical density (OD) was determined by a spectrophotometer at $600 \mathrm{~nm}$.

\section{Antibacterial preparation}

$0.1 \%$ of chlorhexidine diacetate (CHX) and sodium fluoride $(\mathrm{NaF})$ antimicrobial solutions were prepared. For Dr.Wolff's Biorepair it was diluted by distilled water to get $1: 1$ concentration. To prepare the combination between zinccarbonate hydroxyapatite nanoclusters containing mouthwashes and $\mathrm{CHX}$ or $\mathrm{NaF}$; sterilized solutions are used in a ratio $1: 1$

\section{Assessment of the antibacterial activity}

Six sterile glass petri dishes containing the selective media; were prepared. The agar was poured into each petri dish. After setting of the agar, six equidistant wells were made using sterile glass cylinder (cork borer). Then, the punched agar were removed leaving the wells which were later filled with the tested antimicrobials. The $100 \mathrm{ml}$ from each antimicrobial solution were dispensed in the wells. The plates were left for 30 minutes at room temperature to allow diffusion of the tested antimicrobials through the agar; afterwards they were incubated at $37^{\circ} \mathrm{C}$ for 24 hours. For the negative control group, distilled water was used. After 24 hours, all the plates were removed from the incubator and observed for zones of inhibition of microbial growth around the wells containing the tested antimicrobials. 


\section{Statistical analysis}

All the collected data were analyzed using twoway ANOVA system to determine the effect of the antimicrobials and the bacterial strain as well as their interaction on the inhibition zone. One-way ANOVA was used to test the significant difference among the antimicrobials.

\section{RESULT}

For the effect of the tested antibacterial on the Streptococcus mutans bacterial strains, results showed that the mean diameter and standard deviation of inhibition zone $(\mathrm{mm})$ for chlorhexidine (CHX) was 23.9 (2.04) mm, sodium fluoride ( $\mathrm{NaF})$ was $12.2(0.75) \mathrm{mm}$, hydroxyapatite microclusters containing mouthwash (HAPMC) was 18.2 (1.3) $\mathrm{mm}$, HAPMC+CHX was $22.5 \quad(2.6) \mathrm{mm}$ and $\mathrm{HAPMC}+\mathrm{NaF}$ was $18.7(1.8) \mathrm{mm}$.

One way ANOVA showed that the tested antimicrobials had a statistically significant difference in their effects against Streptococcus mutans (Table 1). Chlorhexidine (CHX) and Hydroxyapatite microclusters containing mouthwash with cholrhexidine (HAPMC+CHX) showed the highest antibacterial effect against Streptococcus mutans this was followed by HAPMC alone and Hydroxyapatite microclusters containing mouthwash with $\mathrm{NaF}$ $(\mathrm{HAPMC}+\mathrm{NaF})$ then the $\mathrm{NaF}$ alone.

\section{DISCUSSION}

In the present study, $0.1 \%$ chrlorhexidine showed the highest inhibitory effect against MS. The superiorly have been reported in studies conducted by (Nakamoto et al., 1995) and (Bruschi et al., 2006). Chlorhexidine affects the bacteria using the following mechanism, The bacterial cell wall is negatively charged and contains sulphates and phosphates then dicationic positively charged chlorhexidine is attracted to the negatively charged bacterial cell wall with specific and strong adsorption to phosphate containing compounds that alters the integrity of the bacterial cell membrane and chlorhexidine is attracted to the inner cell membrane by increasing the concentration of chlorhexidine there is progressive damage to the membrane. Chlorhexidine binds to the phospholipids in the inner membrane and there is leakage of low molecular weight compounds like potassium ions then cytoplasm of the cells is chemically precipitated ${ }^{(16)}$.

The efficacy of the sodium fluoride alone or in combination with any tested antimicrobial was less than chlorhexidine against all the tested microorganisms. These were similar results to those obtained by (Malhotra et al., 2011). As mentioned earlier, the main mechanism of the action of fluoride is to maintain equilibrium between the demineralization and remineralization of dental hard tissues rather than antimicrobial action.

\begin{tabular}{|c|c|c|c|c|c|c|c|}
\hline & $\begin{array}{c}\text { Chlorhexidine } \\
\text { (CHX) }\end{array}$ & $\begin{array}{c}\text { Sodium } \\
\text { fluoride } \\
(\mathrm{NaF})\end{array}$ & $\begin{array}{c}\text { Hydroxyapatite } \\
\text { microclusters } \\
\text { containing } \\
\text { mouthwash } \\
\text { (HAPMC) }\end{array}$ & $\begin{array}{c}\text { HAPMC } \\
+ \text { CHX }\end{array}$ & $\begin{array}{c}\text { HAPMC } \\
+ \text { NaF }\end{array}$ & $\begin{array}{c}\text { Distilled } \\
\text { water }\end{array}$ & $P$-value \\
\hline $\begin{array}{c}\text { Streptococcus } \\
\text { mutans }\end{array}$ & $23.9(2.04) \mathrm{A}$ & $\mathbf{1 2 . 2 ( 0 . 7 5 ) B}$ & $\mathbf{1 8 . 2 ( 1 . 3 ) \mathrm { C }}$ & $\mathbf{2 2 . 5 ( 2 . 6 ) \mathrm { A }}$ & $\mathbf{1 8 . 7}(1.8) \mathrm{C}$ & Negative D & $<0.001$ \\
\hline
\end{tabular}

Different letters denoted statistical significance within rows at $P<0.01$ 
Most of the in vivo studies have shown a cariostatic effect of fluoride gels or mouthwashes at $1 \%$ or $2 \%$ fluoride ${ }^{(18)}$. Thus, the observed lower efficacy of sodium fluoride could also be attributed to the lower percentage of fluoride $(0.2 \%$ of $\mathrm{NaF})$ used in this study. This raised concerns for the effective concentration of $\mathrm{NaF}$ as antibacterial versus the human health hazard.

In the present study, the mouthwash containing hydroxyapatite nanoparticles alone or in combination with any tested antimicrobial showed relatively comparable results against the tested bacteria. The mouthwash containing hydroxyapatite nanoparticles from its composition contain $\mathrm{ZnO}$ nanoparticles which had antibacterial properties. It contains sugar alcohols, such as sorbitol and especially xylitol, which are known to have antimicrobial properties ${ }^{(\mathbf{1 9})}$. In addition to these well-accepted effects, the antiadherent but not the antimicrobial effects can be attributed to the size of the adopted biomimetic hydroxyapatite nano particles mimicking the smallest building units of the dental enamel, the enamel crystallites; the respective microclusters of Biorepair are composed of nano sized crystallites ${ }^{(20)}$. These particles might fill the defects caused by dental caries. So, we recommend the combination between CHX and a mouthwash containing hydroxyapatite nanoparticles to gain benefit of the powerful antimicrobial effect of CHX as well as the remeneralizing effect of mouthwash containing hydroxyapatite nanoparticles.

The combination of sodium fluoride with mouthwash containing hydroxyapatite nanoparticles was more effective against MS compared to sodium fluoride alone. This might be due to the possible synergetic effect of their combination on the MS. Still we need further investigations with highly sophisticated tools to detect the direct action of these combinations on the virulence microorganisms.

This study raised many questions among them; can the mouthwash containing hydroxyapatite nanoparticles replace chlorhexidine? Is there a biomimetic mouthwash that could completely eradicate causative microorganisms of dental caries? Still many studies need to be conducted; in vivo and in vitro; to answer these questions.

\section{CONCLUSIONS}

In the light of this study, the following conclusions were drawn:

1- Hydroxyapatite microclusters containing mouthwash had a potential antimicrobial activity against the tested bacterial strains alone or in combination with other antimicrobials.

2- Chlorhexidine is still surpassing the tested antimicrobial agents; however, its combination with hydroxyapatite microclusters containing mouthwash was advantageous against Streptococcus mutans

\section{REFERENCES}

1. Autio-Gold J. The role of chlorhexidine in caries prevention. Oper Dent 2010; 33:710-716.

2. Pallavi SK. Effect of chlorhexidine on mutans Streptococci and dental caries. J Indian Assoc Public Health Dent. 2011; 678-683.

3. Denton GH, Prentice, ML and Burckle. Cainozoic. history of the Antarctic ice sheet. In: Tingey, R.J. (ed.), Geology of Antarctica. Oxford: Oxford University Press, 1991; 365-433.

4. Wang CS, Arnold RR, Trope M, Teixeira FB. Clinical efficiency of $2 \%$ chlorhexidine gel in reducing intracanal bacteria. J Endod 2007; 33: 1283-1289.

5. Soares da Silva LFJ, do Carmo FA, de Almeida Borges VR, Monteiro LM, Rodrigues CR, Cabral LM, de Sousa VP. Preparation and evaluation of lidocaine hydrochloride in cyclodextrin inclusion complexes for development of stable gel in association with chlorhexidine gluconate for urogenital use. Int J Nanomedicine 2011; 6: 1143-1154.

6. Adair SM.Evidence-based use of fluoride in contemporary pediatric dental practice. Pediatr Dent 2006 28;133-142; discussion 192-198.

7. Featherstone JDB. Prevention and reversal of dental caries: role of low level fluoride. Community Dent Oral Epidemiol 1999; 27:31-40. 
8. Hamilton IR. Biochemical Effects of Fluoride on Oral Bacteria. J Dent Res 1990; 69:660-667.

9. Marquis RE, Clock SA, Mota-Meira M. Fluoride and organic weak acids as modulators of microbial physiology. FEMS Microbiol Rev 2003; 26:493-510.

10. Huang Z, Meric G, Liu Z, Ma R, Tang Z, Lejeune P. luxSbased quorum-sensing signaling affects biofilm formation in Streptococcus mutans. J Mol Microbiol Biotechnol 2009; 17:12-19.

11. Rimondini L, Palazzo B, Iafisco M, Canegallo L, Demarosi F, Merlo M, Roveri N. The Remineralizing Effect of Carbonate-Hydroxyapatite Nanocrystals on Dentine. Mater Sci Forum 2007; 539-543:602-605.

12. Cross KJ, Huq NL, Reynolds EC. Casein phosphopeptides in oral health: chemistry and clinical applications. Curr Pharm Des 2007; 13:793-800.

13. Hannig M, Hannig C. Nanomaterials in preventive dentistry. Nat Nanotechnol 2010; 5:565-569.

14. Nakamoto $\mathrm{K}$, Tamamoto $\mathrm{M}$, Hamada $\mathrm{T}$. In vitro effectiveness of mouthrinse against Candida albicans. Int J Prosthodont 1995; 8:486-489.
15. Bruschi ML, Lara EH, Martins $\mathrm{CH}$, Vinholis $\mathrm{AH}$, Casemiro LA, Panzeri H, Gremião MP. Preparation and antimicrobial activity of gelatin micropracticles containing propolis against oral pathogens: Drug Develop Indust Pharm 2006; 32:229-238.

16. Balagopa S, Arjunkumar R. Chlorhexidine: The Gold Standard Antiplaque Agent: J. Pharm. Sci. \& Res, 2013; 5: $270-274$.

17. Malhotra N, Rao SP, Acharya S, Vasudev B. Comparative in vitro evaluation of efficacy of mouthrinses against Streptococcus mutans, Lactobacilli and Candida albicans. Oral Health Prev Dent 2011; 9:261-268.

18. Meurman JH. Ultrastructure, growth, and adherence of Streptococcus mutans after treatment with chlorhexidine and fluoride. Caries Res 1988; 22:283-287.

19. Bowen WH. Food Components and Caries. Adv Dent Res 1994; 8:215-220.

20. Sarikaya M, Tamerler C, Jen AK-Y, Schulten K, Baneyx F. Molecular biomimetics: nanotechnology through biology. Nat Mater 2003; 2:577-585. 